\title{
Experimental study on the effect of welding speed and tool pin profiles on AA6082-O aluminium friction stir welded butt joints
}

\author{
H. S. Patil ${ }^{*}$, S. N. Soman ${ }^{2}$ \\ ${ }^{1 *}$ Department of Mechanical Engineering, M.G. Institute of Tech Education and Research Centre, Navsari - 396450, INDIA \\ ${ }^{2}$ Department of Metallurgy \& Material Science, Faculty of Engineering \& Technology, M. S. University of Baroda, Vadodra-1, INDIA \\ *Corresponding Author's E-mail: hspatil12@rediffmail.com
}

\begin{abstract}
Friction stir welding (FSW) is a novel solid state welding process for joining metallic alloys and has emerged as an alternative technology used in high strength alloys that are difficult to join with conventional techniques. The applications of FSW process are found in several industries such as aerospace, rail, automotive and marine industries for joining aluminium, magnesium and copper alloys. The FSW process parameters such as rotational speed, welding speed, axial force and attack angle play vital roles in the analysis of weld quality. The aim of this research study is to investigate the effects of different welding speeds and tool pin profiles on the weld quality of AA6082-O aluminium. This material has gathered wide acceptance in the fabrication of light weight structures requiring a high strength-to-weight ratio. Tri-flutes and taper screw thread pin are used as tool pin profiles in this research. The appearance of the weld is well and no obvious defect is found using these tools. Consequently, the obtained results explain the variation of stress as a function of strain and the effect of different welding speed and pin profiles on yield strength ultimate tensile strength and elongation. The friction stir welded plates of AA6082-O by using the taper screw thread pin profile reaches the ultimate tensile strength of $92.30 \%$ of the base metal ultimate strength and \% elongation of $27.58 \%$.
\end{abstract}

Keywords: Friction stir welding, AA6082-O aluminium alloy, welding speed, mechanical properties

\section{Introduction}

Friction stir welding (FSW) is a solid-state joining process developed and patented by the The Welding Institute (Thomas et al, 1992; Dawes et al., 1996), and has emerged as a welding technique used in high strength alloys (2xxx, 6xxx, 7xxx and 8xxx series) for aerospace, automotive and marine applications (Nicholas et al., 2002) that were difficult to join with conventional techniques. This technique is attractive for joining high strength aluminium alloys since there is far lower heat input during the process compared with conventional welding methods such as TIG or MIG. This solid state process leads to minimal micro-structural changes and better mechanical properties than conventional welding (Nicholas et al., 2002; Ericsson et al., 2003; Ellis et al., 1996). The process was developed initially for aluminium alloys, but since then, FSW was found suitable for joining a large number of materials. Conventional fusion welding of aluminium alloys often produces a weld which suffers from defects, such as porosity developed as a consequence of entrapped gas not being able to escape from the weld pool during solidification. In contrast, with FSW, the interaction of a non-consumable tool rotating and traversing along the joint line creates a welded joint through viscoplastic deformation and consequent heat dissipation resulting in temperatures below the melting temperature of the materials being joined. Other interesting benefits of FSW compared to fusion processes are low distortion, excellent mechanical properties in the weld zone, execution without a shielding gas, and suitability to weld all aluminium alloys (Mishra \& Mahoney, 2007). Some authors analysed the influence of the tool rotation speed (Cavaliere et al., 2008; Moreira et al., 2009), welding speed (Cavaliere, 2009; Lee et al, 2003; Simar et al., 2008; Peel, 2006) and both parameters simultaneously on the microstructure and mechanical properties of 6XXX welds (Lim et al., 2004; Ren et al., 2007; Aydın et al., 2009). Recently, experimental work has been carried out for welding of tube to tube plate by using FSW process and it is also investigated numerically (Senthil Kumaran et al., 2010). These works enhance the difficulty in evaluating the dependence of the thermal and mechanical properties on weld parameters. In this investigation, an attempt has been made to understand the effect of tool pin profiles and different welding speed on the weld 
quality of AA6082-O aluminium using FSW process. Tri-flute and taper screw thread pin are used as tool pin profiles in this research. The pin traveled longitudinally at different welding speed $(\mathrm{mm} / \mathrm{min})$ and the tool rotation speed was held constant at $1200 \mathrm{rpm}$ in all of the experiments. Consequently, the appearance of the weld for different welding speed has been examined by using X-ray radiography technique and the impact of the stress as a function of strain and the effect of different welding speed and pin profiles on yield strength and elongation are analyzed.

\section{Friction Stir Welding Process}

FSW is produced by rotating and plunging a specially-designed cylindrical, shouldered tool with a small diameter pin into the joint line between two butted plates. Frictional heat causes the metal to soften and allows the tool to traverse along the joint line. The FSW process is divided in two famous processes defined as lap joints and butt joints. In this research, the process of butt joints is investigated. The two plates are clamped on a rigid backplate. The fixturing prevents the plates from spreading apart or lifting during welding. The welding tool, consisting of a shank, shoulder and pin, is then rotated to a prescribed speed. The tool is slowly plunged into the workpiece material at the butt line, until the shoulder of the tool forcibly contacts the upper surface of the material and the pin is a short distance from the back plate. A downward force is applied to maintain the contact and a short dwell time is observed to allow for the development of the thermal fields for preheating and softening the material along the joint line. At this point, a lateral force is applied in the direction of welding (travel direction) and the tool is forcibly traversed along the butt line until it reaches the end of the weld. Alternately, the plates could be moved while the rotating tool remains stationary. Upon reaching the end of the weld, the tool is withdrawn while it is still being rotated. As the pin is withdrawn, it leaves a keyhole at the end of the weld. The FSW process of butt joints is shown in Figure 1(Mishra \& Mahoney, 2007).

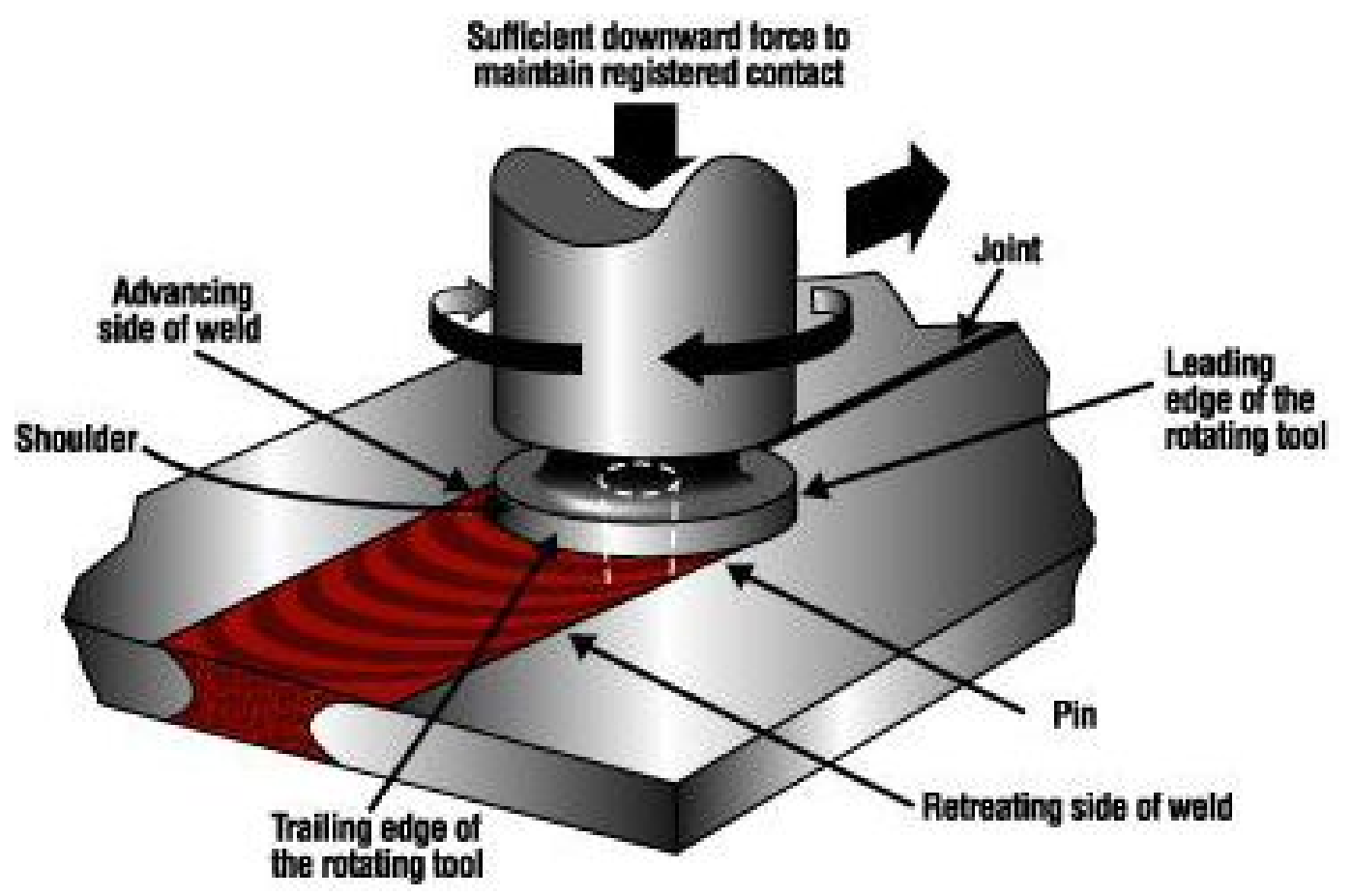

Figure 1 Principle of the FSW process for butt joints (Mishra and Mahoney, 2007)

FSW process generates three distinct micro-structural zones shown in Figure 2 (Mishra and Mahoney, 2007), A-the nugget zone, B-the thermo-mechanically affected zone (TMAZ) and C- the heat affected zone (HAZ). The nugget is the region through which the tool piece pin passes, and thus experiences high deformation and high heat. It generally consists of fine equiaxed grains due to full recrystallisation. The TMAZ adjacent to the nugget is the region where the metal is plastically deformed as well as heated, but this is not sufficient to cause recrystallisation. The HAZ experiences only a heating effect, with no mechanical deformation. 


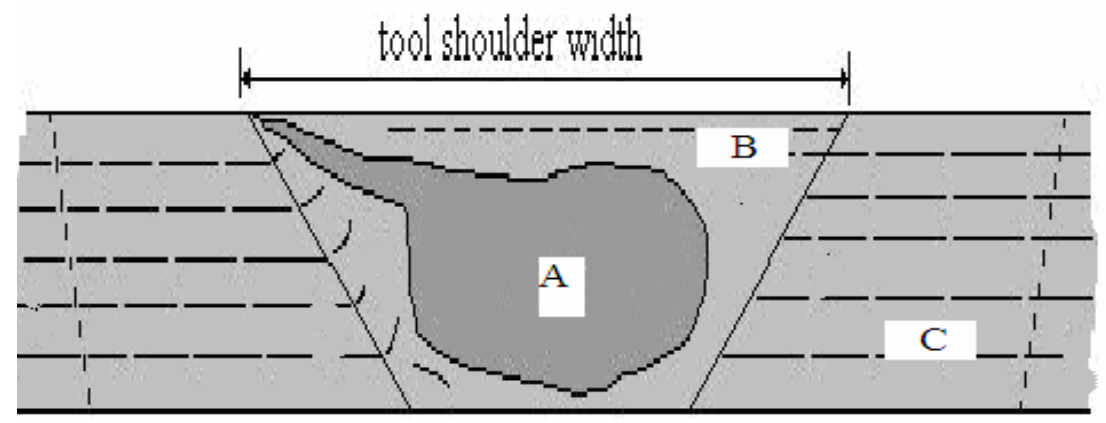

Figure-2 Micro-structural features of Friction Stir Welds (Mishra and Mahoney, 2007)

\section{Experimental work}

The friction stir welds have been carried out by using a properly designed clamping fixture that allows the user to fix the two sheets $(160 \mathrm{~mm} \times 60 \mathrm{~mm})$ with the rolled plate of $5 \mathrm{~mm}$ thickness to be butt welded on a CNC vertical milling machine. Figure-3 shows the vertical CNC milling machine used for experimental work.

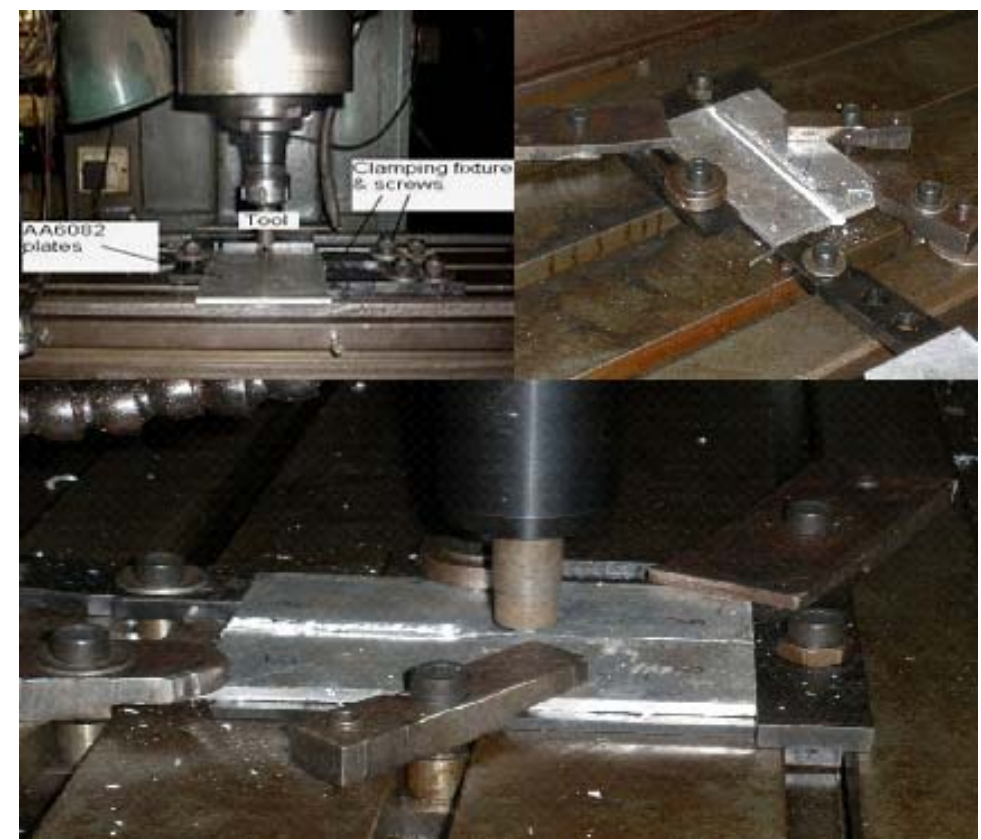

Figure 3 Experimental Setup describing clamping and welding of FSW plates

In this investigation, the base materials, AA6082-O, which is a precipitation hardened aluminum alloy widely used in aerospace applications due to its high strength was used. FSW plates were examined using X-ray radiography. There was no apparent defects in welded plates. The welding parameters used were rotational speed of $1200 \mathrm{rpm}$, welding speed of 60 to $85 \mathrm{~mm} / \mathrm{sec}$. The mechanical and chemical properties of AA6082-O are shown in Table 1 and Table 2, respectively.

Table-1 Mechanical properties of base metal

\begin{tabular}{|c|c|c|c|}
\hline Material & Yield stress (MPa) & Ultimate Strength (MPa) & \% Elongation \\
\hline AA6082-O & 60 & 130 & 27 \\
\hline
\end{tabular}


Table 2.Chemical compositions (wt. \%) of the base metal

\begin{tabular}{|c|l|}
\hline Element & \multicolumn{1}{|c|}{$\%$ Present } \\
\hline $\mathrm{Si}$ & 0.7 to $1.3 \%$ \\
\hline $\mathrm{Fe}$ & $0.5 \%$ \\
\hline $\mathrm{Cu}$ & $0.1 \%$ \\
\hline $\mathrm{Mn}$ & 0.4 to $1.0 \%$ \\
\hline $\mathrm{Mg}$ & 0.6 to $1.2 \%$ \\
\hline $\mathrm{Zn}$ & $0.2 \%$ \\
\hline $\mathrm{Ti}$ & $0.1 \%$ \\
\hline $\mathrm{Cr}$ & $0.25 \%$ \\
\hline $\mathrm{Al}$ & Balance \\
\hline
\end{tabular}

3.1 Configuration of welding tool geometry

Figure 4 shows the image of two different tool pin profiles used in this research work in order to fabricate the joints in which the upper one is the taper screw thread pin and the lower one is the tri-flute pin.

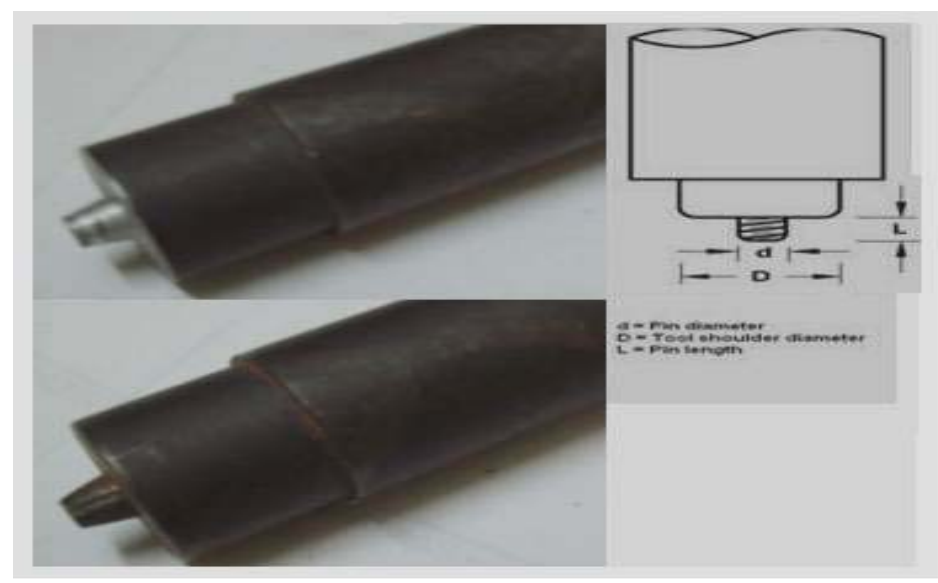

Figure 4 Image of the tool pin profiles used in this study

The geometrical configuration and the chemical composition of the tools are shown in Table 3 and Table 4, respectively.

Table 3 Pin geometry

\begin{tabular}{|l|l|l|}
\hline $\begin{array}{l}\text { Description of } \\
\text { the pin }\end{array}$ & $\begin{array}{l}\text { Big diameter } \\
\text { of the pin }\end{array}$ & $\begin{array}{l}\text { Small diameter } \\
\text { of the pin }\end{array}$ \\
\hline Tri-flute pin & $5.50 \mathrm{~mm}$ & $4.90 \mathrm{~mm}$ \\
\hline Taper screw thread pin & $5.54 \mathrm{~mm}$ & $4.30 \mathrm{~mm}$ \\
\hline
\end{tabular}

Table 4 Chemical composition (wt. \%) of tool

\begin{tabular}{|c|l|}
\hline Element & \multicolumn{1}{|c|}{$\%$ Present } \\
\hline $\mathrm{Si}$ & 0.3 to $0.4 \%$ \\
\hline $\mathrm{C}$ & 1.8 to $2.1 \%$ \\
\hline $\mathrm{Mn}$ & 0.3 to $0.4 \%$ \\
\hline $\mathrm{Cr}$ & 11.8 to $12.2 \%$ \\
\hline
\end{tabular}




\subsection{Welding parameter and tool dimensions}

The initial joint configuration was obtained by securing the plates in position using mechanical clamps. The direction of welding was normal to the rolling direction. Single pass welding procedure was used to fabricate the joints. The welding parameters used to fabricate the joints are presented in Table 5.

Table-5 Welding parameter and tool dimensions

\begin{tabular}{|l|l|}
\hline Rotating speeds(rpm) & 1200 \\
\hline Welding speeds (mm/min) & $60,70,75,85$ \\
\hline Pin length $(\mathrm{mm})$ & 4.7 \\
\hline Tool shoulder diameter $(\mathrm{mm})$ & 18 \\
\hline
\end{tabular}

\subsection{Specimen preparation for tensile testing}

The welded joints are sliced using power hacksaw and then machined to the required dimensions to prepare tensile specimens as shown in Figure 5. These specimens are taken in the normal direction of the weld. The specimen is loaded and tensile specimen undergoes deformation.

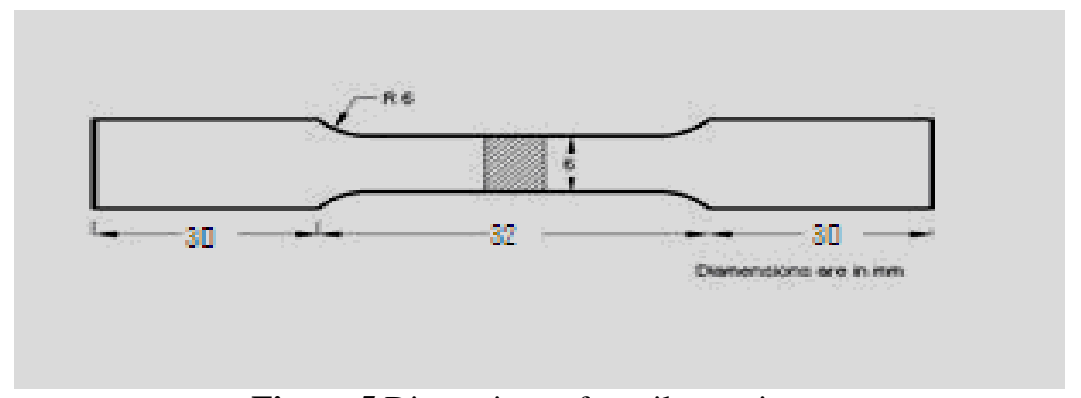

Figure 5 Dimensions of tensile specimen

Tensile tests were performed to determine the mechanical properties of the material such as yield strength, tensile strength and percentage of elongation have been evaluated. Three specimens are tested at each condition and average of the results of three specimens is measured as a final result.

\section{Result and Discussion}

The predicted results are plotted as graphs and they are displayed in Figure 6 to11. The plotted graphs can be effectively used to understand the effect of FSW process parameters such as welding speed, tool profiles on tensile strength of friction stir welded AA6082-O aluminium alloy joints.

\subsection{Effect of tool pin profile and welding speed on the tensile properties}

Tensile properties such as yield strength, tensile strength and percentage of elongation have been evaluated. At each condition specimens are tested and average of the results of specimens is presented as the outcome of this research work. Figures 6 and 7 show the engineering stress-strain relationship of the welded products for taper screw thread and tri-flute pin profiles respectively.

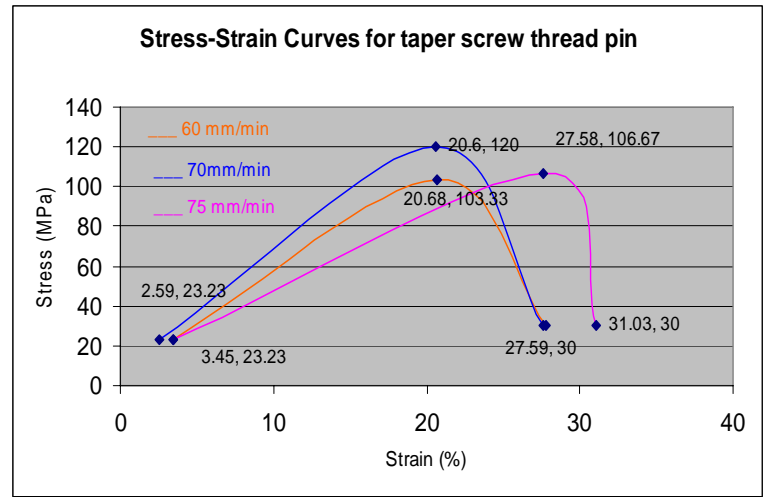

Figure 6 Stress Strain Curves for taper screw thread pin 
From these figures, it can be observed that the tool pin profile and welding speed are having influence on the obtained stress of the FSW joints.

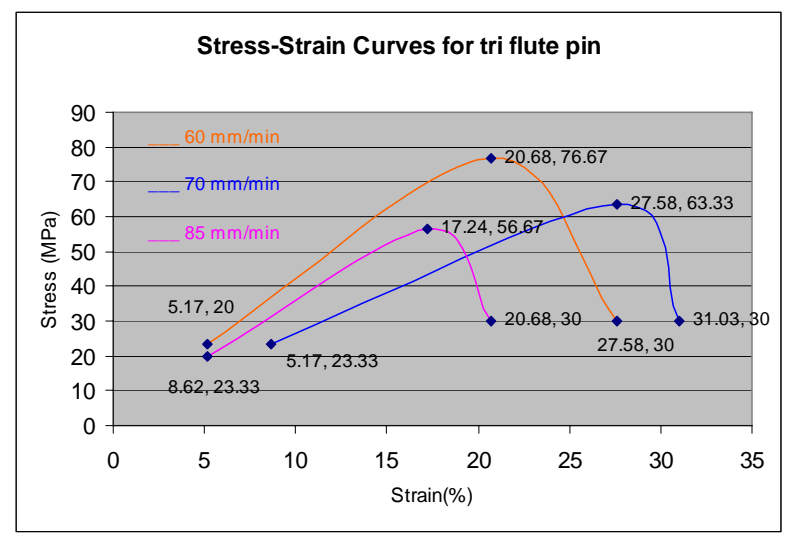

Figure 7 Stress Strain Curves for tri-flute pin

Figures 8 and 9 illustrate the variation of engineering stress and engineering strain for taper screw thread and tri-flute pin profiles at $60,70 \mathrm{~mm} / \mathrm{min}$ respectively.

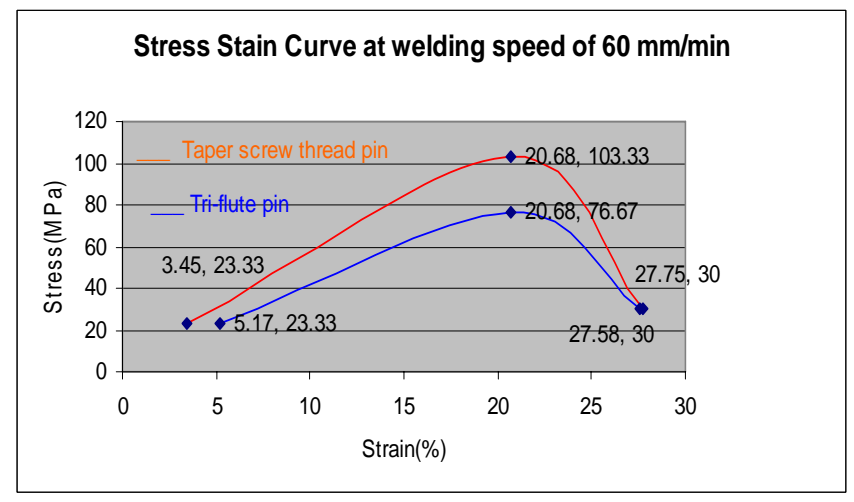

Figure 8 Stress Strain Curves at welding speed of $60 \mathrm{~mm} / \mathrm{min}$

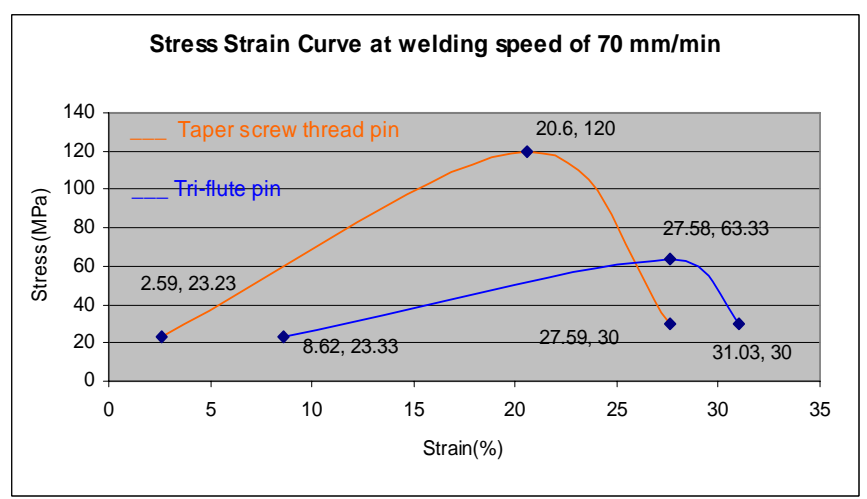

Figure 9 Stress Strain Curves at welding speed of $70 \mathrm{~mm} / \mathrm{min}$

Figure 10 illustrates the effect of tool pin profiles and welding speed on ultimate tensile strength of FSW joint. As observed, the taper screw thread joints fabricated at the welding speed of $60 \mathrm{~mm} / \mathrm{min}$ have shown lower tensile strength (ultimate and yield strength) compared to the joints fabricated at a speed of $70 \mathrm{~mm} / \mathrm{min}$. Similarly, the joints fabricated at the welding speed of $75 \mathrm{~mm} / \mathrm{min}$ have shown lower tensile strength compared to the joints fabricated at a welding speed of $70 \mathrm{~mm} / \mathrm{min}$. The joints fabricated at a welding speed of $70 \mathrm{~mm} / \mathrm{min}$ show superior tensile strength for this pin profile. Similarly, this effect can be seen for tri-flute joints. The tri-flute joints fabricated at the welding speed of $60 \mathrm{~mm} / \mathrm{min}$ have demonstrated more tensile strength in comparison with other welding speed $70,85 \mathrm{~mm} / \mathrm{min}$. 


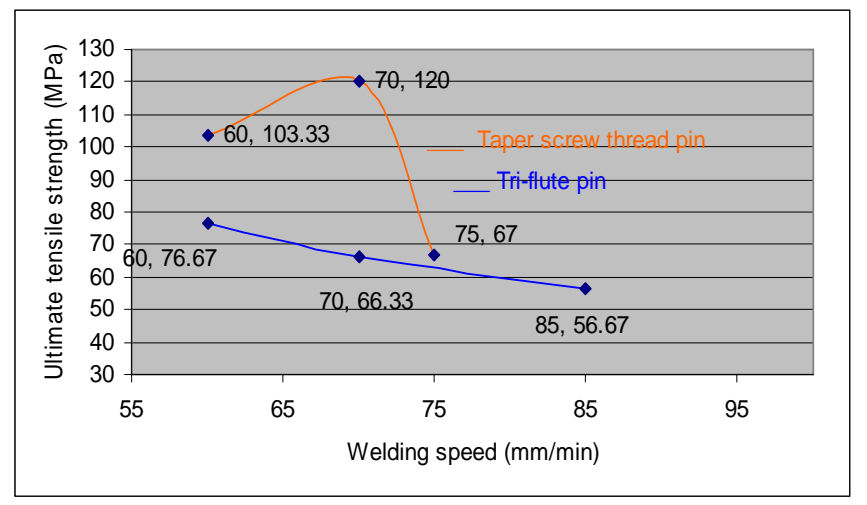

Figure 10 Effect of tool pin profile and welding speed on UTS

Figure 11 presents the variation of \% elongation with welding speed for these two joints. The percentage of elongation for taper screw thread pin shoots up as a result of increasing in the welding speed from $20 \%$ at $60 \mathrm{~mm} / \mathrm{min}$ to approximately $27.58 \%$ at $75 \mathrm{~mm} / \mathrm{min}$. Similarly, for tri-flute pin profile the elongation percentage decreases at welding speed of $85 \mathrm{~mm} / \mathrm{min}$.

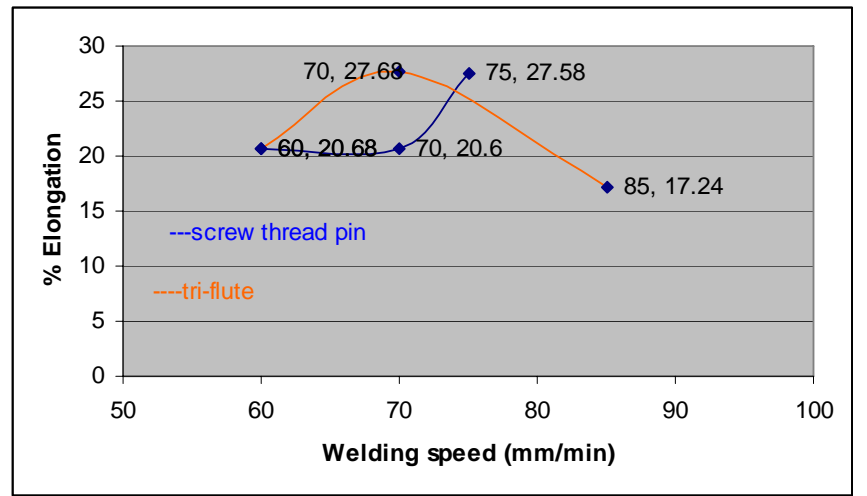

Figure 11 Effect of tool pin profile and welding speed on the elongation

\section{Conclusion}

In this paper, AA 6082-O alloy was welded by using FSW process. Two different friction stir pin profiles were designed to study the influence of the pin geometry on the weld shape and mechanical properties. Also, the effect of different welding speed is investigated in this research. From this research, the following conclusions are derived:

- The effect of tool pin profile and welding speed on the appearance of the weld is presented and no obvious defect was found.

- The results indicate that pin profile has a significant effect on the joint structure and the mechanical properties.

- It is found that the joint fabricated using taper screw thread pin exhibits superior tensile properties compared tri -flute pin profile, irrespective of welding speed.

- The ultimate tensile strength of the taper screw thread reaches to the $92.30 \%$ of the base metal ultimate strength.

- The tri-flute pin ultimate strength goes up to the $58.97 \%$ of the base metal ultimate strength.

- The taper screw thread joints fabricated at the welding speed of $70 \mathrm{~mm} / \mathrm{min}$ have demonstrated more ultimate and yield strength in comparison with other welding speed of $60,75 \mathrm{~mm} / \mathrm{min}$.

- The four-flute joints fabricated at a welding speed of $60 \mathrm{~mm} / \mathrm{sec}$ show superior tensile properties compared to 70 , $85 \mathrm{~mm} / \mathrm{min}$.

- The percentage of elongation increases due to increasing the welding speed.

Finally, we conclude that the friction stir welded plates of AA6082-O by using the taper screw thread pin profile at a welding speed of $70 \mathrm{~mm} / \mathrm{min}$ reaches the ultimate tensile strength of $92.30 \%$ of the base metal ultimate strength and \% elongation of $27.58 \%$.

\section{Nomenclature}

FSW friction stir welding

TIG tungsten inert gas 
MIG metal inert gas

TMAZ thermo-mechanically affected zone

HAZ heat affected zone

\section{Acknowledgements}

The authors would like to thank Mr. Devang Desai at EM Tech Fabrication, Navsari, for facilities and support during experiment

\section{References}

Aydın H., Bayram A., Agah U., Akay K. S., 2009.Tensile properties of friction stir welded joints of 2024 aluminum alloys in different heat-treated-state, Materials and Design, Vol.30, pp. 2211-2221.

Cavaliere P., Santis A. De., Panella F., Squillace A. 2009. Effect of welding parameters on mechanical and microstructural properties of dissimilar AA6082-AA2024 joints produced by friction stir welding, Materials and Design, Vol. 30, pp. 609-616.

Dawes C.J., Thomas W.M., 1996. Friction stir process welds of aluminum alloys, Welding Journal, Vol.75, No.3, pp.41-45.

Ericsson M., Sandstro R. 2003. Influence of welding speed on the fatigue of friction stir welds, and comparison with MIG and TIG, International Journal of Fatigue, Vol.25, pp. 1379-1387.

Ellis M.B.D., Strangwood M. 1996. Welding of rapidly solidified Alloy-8009 preliminary study, Material Science \& Technology, Vol. 12, pp. 970-977.

Lim S., Kim S., Lee C.G., Kim S.J. 2004. Tensile behavior of friction-stir-welded Al 6061- T651, Metallurgical and Material Transactions A, Vol. 35, No.9, pp. 2829-2835.

Mishra R.M., Mahoney M.W. 2007. Friction stir welding \& processing, ASM International, pp.360

Cavaliere P., Squillace A., Panella F. 2008. Effect of welding parameters on mechanical \& micro-structural properties of AA6082 joints produced by friction stir welding, Journal of Materials Processing Technology, Vol.200, No.1-3, pp.364-372

Moreira P. M. G. P., Santos T. Tavares S. M. O, Richter-Trummer V. 2009. Mechanical and metallurgical characterization of friction stir welding joints of AA6061-T6 with AA6082-T6, Materials and Design, Vol. 30, pp.180-187.

Lee W.B., Yeon Y.M., Jung S.B. 2003. Evaluation of the microstructure and mechanical properties of friction stir welded 6005 aluminum alloy, Material Science \& Technology, Vol.19, No.11, pp.1513-1518.

Peel M.J., Steuwer A., Withers P.J., Dickerson T., Shi Q., Shercliff H. 2006. Dissimilar friction stir welds in AA5083-AA6082. Part I: process parameter effects on thermal history and weld properties, Metallurgical and Material Transactions A, Vol. 37, pp. 2183-2193.

Ren S.R., Ma Z.Y., Chen L.Q. 2007. Effect of welding parameters on tensile properties and fracture behavior of friction stir welded Al-Mg-Si alloy, Scripta Materialia,Vol.56, No.1, pp.69-72.

Simar A., Brechet Y., Meester B. de., Denquin A., Pardoen T. 2008. Microstructure, local and global mechanical properties of friction stir welds in aluminium alloy 6005A-T6. Material Science \& Engineering, Vol. 486, No.1-2, pp. 85-95.

Thomas W.M., Nicholas E.D., Needham J.C., Murch M.G., Templesmith P., Dawes C.J. 1992. Improvements relating to friction welding, WO/1993/010935, International Patent Number, PCT/GB92/02203 TWI.

Thomas W.M., Nicholas E. D., Watts E.R., Staines D.G. 2002. Friction based welding technology for aluminium, Material Science Forum, Vols.396-402, pp.1543-1548.

Senthil Kumaran S., Muthukumaran S., Vinodh S. 2010. Experimental and numerical investigation of weld joints produced by friction welding of tube to tube plate using an external tool, International Journal of Engineering, Science and Technology, Vol. 2, No.2 pp.109-117.

\section{Biographical notes}

Prof. H. S. Patil is Ph.D. research scholar \& Assistant Professor of Department of Mechanical Engineering, at M.G. Institute of Tech Education and Research Centre, Navsari - 396450, India, E-mail: hspatil12@rediffmail.com

Dr. S. N. Soman is Reader of Department of Metallurgy \& Material Science, in Faculty of Engineering \& Technology, M. S. University of Baroda, Vadodra-1, India. He did his Ph.D. from IIT Bombay. E-mail: somansn@yahoo.com

Received July 2010

Accepted August 2010

Final acceptance in revised form September 2010 